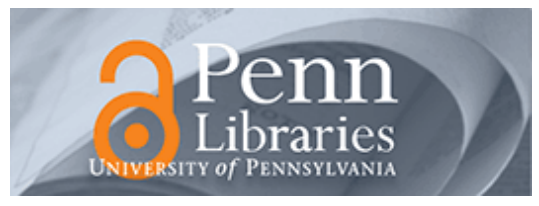

University of Pennsylvania ScholarlyCommons

\title{
Poaching and the Misappropriation of Information: Transaction Risks of Information Exchange
}

\author{
Eric K. Clemons \\ University of Pennsylvania \\ Lorin M. Hitt \\ University of Pennsylvania
}

Follow this and additional works at: https://repository.upenn.edu/mgmt_papers

Part of the Management Sciences and Quantitative Methods Commons

\section{Recommended Citation}

Clemons, E. K., \& Hitt, L. M. (2004). Poaching and the Misappropriation of Information: Transaction Risks of Information Exchange. Journal of Management Information Systems, 21 (2), 87-107. http://dx.doi.org/ 10.1080/07421222.2004.11045802

This paper is posted at ScholarlyCommons. https://repository.upenn.edu/mgmt_papers/281

For more information, please contact repository@pobox.upenn.edu. 


\title{
Poaching and the Misappropriation of Information: Transaction Risks of Information Exchange
}

\author{
Abstract \\ We address the concept of poaching, the risk that in any transactional relationship, information that is \\ transferred between parties for purposes specified in the contract will deliberately be used by the \\ receiving party for purposes outside the contract, to its own economic benefit, and to the detriment of the \\ party that provided the information. We argue that this form of transactional risk, a component of \\ transaction costs, is increasingly important in our service-centered, information-driven, postindustrial \\ economy. Using case examples and a discussion of the related literature, we demonstrate and discuss \\ the conditions under which shared information creates the potential for poaching, examine the impact \\ and efficacy of traditional remedies for contractual problems in managing poaching, and identify \\ additional mechanisms for managing poaching risk. Our analysis suggests that these risks and their \\ remedies are fundamentally different in nature from those considered in previous theories of supplier \\ relations and contractual governance.

\section{Keywords} \\ economic analysis of information, incomplete contracts, information sharing, intellectual property, \\ managing risks, transaction cost theory

\section{Disciplines} \\ Management Sciences and Quantitative Methods
}




\section{Poaching and the Misappropriation of Information: An Increasingly Important Form of Opportunism}

September, 2000

Eric K. Clemons

University of Pennsylvania, Wharton School

1300 Steinberg Hall-Dietrich Hall

Philadelphia, PA 19104

clemons@wharton.upenn.edu

Lorin M. Hitt

University of Pennsylvania, Wharton School

1300 Steinberg Hall-Dietrich Hall

Philadelphia, PA 19104

lhitt@wharton.upenn.edu 


\section{Poaching and the Misappropriation of Information:}

\section{An Increasingly Important Form of Opportunism}

We introduce the concept of poaching, the risk that in any contractual relationship information that is transferred between parties for purposes specified in the contract will deliberately be used by the receiving party, for purposes outside the contract, to its own economic benefit, and to the detriment of the party that provided the information. We argue that this form of transaction risk, a component of transactions costs, is increasingly important in our service-centered, informationdriven, post-industrial economy. More specifically, we demonstrate the following:

- This form of risk is increasingly significant as firms form alliances and cooperative ventures for speed to market in an internet economy, and as new entrants and smaller firms form these alliances to gain access to scarce, traditional resources.

- This form of risk has not previously been studied in the more traditional, neoclassical transactions cost economics literature, as the form of asset under consideration is not consumed through use and cannot be returned after contract termination, making allocation of ownership, the cornerstone of transactions cost and incomplete contracts theories, ineffectual.

Moreover, while we address the principal questions of transactions costs economics - how can risks be managed to increase the likelihood that economically efficient contracts can actually be reached - and use the terminology and philosophy of this discipline, the problem we study and the findings we derive are fundamentally different from those that have come before this work. Combining case examples and mathematical modeling, we show and discuss the conditions under which shared information creates the potential for poaching, examine the impact and efficacy of traditional remedies for contractual problems, and identify new mechanisms for managing poaching risk. Our analysis suggests the presence of poaching risk can substantially alter the predictions of transactions cost economics and other theories of inter-firm relationships, and warrants greater focus by both researchers and practitioners in the design of contracts for information technology procurement and technology-based services. 


\section{Introduction}

We introduce the concept of poaching, the risk that in any contractual relationship, information that is transferred between parties for purposes specified in the contract will deliberately be used by the receiving party, for purposes outside the contract, to its own economic benefit, and to the detriment of the party that provided the information. We argue that this form of transaction risk, a component of transactions costs, is increasingly important in our service-centered, informationdriven, post-industrial economy. Moreover, we argue that it warrants greater focus, both from researchers examining the assessment of transactional risks and in the design of formal contracts governing commercial exchange.

The increased use of contractors for information technology-related business services such as consulting, technology infrastructure management, provision of application services, and systems development has vastly increased the opportunities for poaching in recent years. Similarly, the increased outsourcing of service activities to third party service firms (e.g., call centers, data processors), and increasingly, electronic commerce order fulfillment services, often require substantial amounts of private customer data to accomplish their tasks in an efficient and effective manner. In both cases, these data, processes and procedures may have substantial resale value, possibly exceeding the value of the contract. Similar concerns also arise in manufacturing settings, with the growth of offshore contract manufacturing facilities and an increasingly cooperative approach on research and development between buyers and suppliers.

The situation faced by new internet-based businesses such as Priceline.com is typical of the risks created by poaching. In order to capitalize on their patented "name your own price" approach to pricing, they have cooperated with other electronic travel sites to achieve rapid market entry. A necessary by-product of this strategy, which appeared desirable at the time, is that their potential competitors are now well informed about aspects of their technology that goes far beyond what was disclosed in the patent. In some cases these former partners are now direct competitors in some segments of their business, a fact which was not foreseen at the time of the contract. The financial risk created by these threats is many times the value of the original contract and in the 
medium term may threaten the survival of the company if not vigorously and successfully defended.

Economic analysis of interfirm relationships has primarily been based on one of three perspectives from organizational economics: transactions cost economics (Coase, 1937; Klein, Crawford and Alchian, 1978; Williamson, 1975), agency theory (Alchian and Demsetz, 1972; Jensen and Meckling, 1976) and incomplete contracts theory (Grossman and Hart, 1986; Hart and Moore, 1990). These perspectives cover a wide range of possible contractual problems that arise from asymmetric information, bounded rationality, and irreversible investments. Information about vendor behaviors or external market conditions plays a large role in these theories, with the general perspective that more or better information will usually improve contractual performance. Perhaps surprisingly, there has been little attention paid the behavior of information as an asset (with the exception of Brynjolfsson, 1994 and VanAlstyne, Brynjolfsson and Madnick, 1994), and no attention paid to the idea that information assets might be detrimentally used beyond a contractual relationship (with the exception of Clemons and Row, 1992 and Clemons, Reddi and Row, 1990). In contrast, the literature on R\&D has extensively examined the issue of the sale or transfer of intellectual assets, but typically assumes that some form of protection such as a patent is in place or that potential for expropriation is foreseen and deliberately considered in contracting among the parties that might value the asset (see Anton and Yao, 1994, especially fn 3). The R\&D and patents literature has also examined ex-ante incentives to invest in creative activity given the possibilities of ex-post appropriation. This literature has not focused on the economic inefficiencies that arise from the transfer of existing information as a by-product of a contractual exchange.

The paper is an analysis of how the increased use and sharing of information assets in a contractual exchange can lead to a set of risks, different from those that have been previously considered in work in transactions cost economics, incomplete contracts theory or other theories of contracting and governance. This is emerging an important issue in information systems, as almost all systems development and IS outsourcing contracts create these risks (see our examples section for several variants). This is especially important for e-commerce businesses (e.g., 
Priceline, now in litigation with Microsoft) that must rely on outside service providers for many operational functions. While this cooperation is essential for rapid market entry by firms with few assets other than their information and intellectual property, this cooperation itself opens these firms up to exploitation as a result of the transfer of information; that is, while this information is typically the only asset that these firms can contribute to their cooperative ventures, it is also frequently their most valuable asset and their only source of advantage. The risks we study here have also become more prominent over time, as the economy moves increasingly towards service industries and towards information-intensive production approaches, and as firms are increasingly relying on outside contractors to support critical business processes. In many cases, a careful analysis of the potential for information poaching will lead to a different prediction about the risks of contracting and the remedies for these risks in outsourcing. As importantly, the form of risk we study has generally not received significant attention from economists in the past, largely because it is associated with assets that cannot be returned and are not consumed during use, a form of asset that was simply not relevant in previous industries, and, indeed, did not exist in the context of heavy manufacturing.

While we draw heavily on previous work in the theory and practice of contracting, our goal is to propose an extension to these theories, utilizing approaches, argument style and principles that are common in contract theory and organizational economics. In particular, although our model is different we are indeed addressing a central question: when can the risks of contracting be managed, and when do these risks preclude the reaching of social efficient and economically efficient wealth-creating contracts?

In Section 2, we survey the existing literature on contracting and identify similarities and differences between poaching and other contractual problems. In Section 3 we formally define poaching and utilize case examples to illustrate the conditions under which poaching can occur, and by analogy with research in transactions cost economics, the conditions under which beneficial contracts may fail to be reached. In Section 4 we formalize these observations in a theoretical model. In Section 5, we evaluate the efficacy of standard contractual remedies in addressing poaching and we identify situations where certain types of remedies designed to 
address other contractual problems may have unintended and negative consequences when there is potential for poaching. We present a brief conclusion in Section 6.

\section{Previous Literature}

\subsection{Transactions Cost Economics and Principal Agent Theories}

To date, the dominant approach to evaluating interfirm contractual arrangements is the transactions cost economics (TCE) approach. TCE addresses fundamental questions in the breakdown $^{1}$ of markets, such as the existence of firms as stable employers or the choice between vertical integration and spot contracting.

Traditionally, mainstream work in TCE examines how different governance structures economize on the combination of production costs and transactions costs. Earlier writers on the issue of transaction governance (such as Coase, 1937) emphasized the role of frictional costs - the cost of locating suppliers, negotiating agreements and writing contracts - as the impediment to contracting and a motivation for the existence of firms. Williamson extended this to focus on "transaction risks," which arise due to bounded rationality and the potential for opportunism. Unlike frictional costs, which are direct, most of the costs associated with transaction risks are implicit: the lesser of the cost of opportunism or the required investment to prevent opportunism from occurring. For example, numerous costly mechanisms have been devised to protect parties in a contract, such as monitoring, performance measurement, bonding, or dual-sourcing. At an extreme, the opportunism risks are so great that firms forego contracting altogether in favor of “uneconomic vertical integration". Chandler (1977) provides numerous historical examples of users of critical resources, like refrigerated rail cars for hauling meat in the summer, for which the dangers of relying on an outside vendor were so great that firms did not use the rental or spot market, and instead owned these resources themselves.

\footnotetext{
${ }^{1}$ We use breakdown in the same sense that Williamson and Coase did - not as collapse of market valuations, but in the replacement of market institutions by potentially less efficient non-market mechanisms.
} 
The emphasis of transactions cost analysis has historically been in two areas: moral hazard (principally "shirking" <<use the Clemons and Row reference, 1992〉>) and hold-up (also referred to as "opportunistic renegotiation" <<again, use the Clemons and Row reference.>>). Shirking represents a classic example of the principal-agent problem (Alchian and Demsetz, 1972; Jensen and Meckling, 1976), where a principal seeks to hire an agent to perform a task. In cases where effort is costly to the agent and the outcome of the effort is difficult to measure, the agent will exert less effort than is optimal for the principal, thus increasing his or her own benefit at the expense of the principal. The usual remedies for this problem are monitoring to detect underperformance by the agent or incentive contracting where the principal and agent share the benefits of effort and thus have better aligned incentives. In some cases, when the principal cannot be satisfied that the agent will perform satisfactorily, or where the uncertainty of performance is so great that the agent cannot bear the risk of an incentive contract, the parties may fail to reach a contract altogether. Numerous examples of shirking as a problem exist throughout the literature, and the problems caused by shirking have the potential to play a role in almost any contractual relationship.

Hold-up represents a renegotiation of the terms of an agreement due to changes in bargaining power after a contract is signed. In the economics literature, the emphasis has been placed on hold-up arising from switching costs, which principally arise due to relationship specific investment (Williamson, 1975; Klein, Crawford and Alchian, 1988; Tirole, 1988) and post contractual small-numbers bargaining (Kleindorfer and Kneips, 1982). Examples discussed in the literature include co-located facilities (site specificity), dedicated skills or training (human capital specificity), or unusual investments in specialized machinery or services for a particular customer (see a discussion in Tirole, 1988, p. 21). In each case, one party makes an investment which is more valuable within an existing relationship than on the open market. The primary remedy for hold-up is establish the rules for future trade as clearly as possible, build in mechanisms that adjust the contract to account for foreseeable but uncertain future conditions (e.g., commodities prices), and when this is not adequate, to forego contracting altogether. In actual contracts, these efforts to reduce hold-up appear as longer-term contracting, "escalator clauses" and other market-based repricing schemes, or shared investment in dedicated facilities. However, even with a well- 
designed contract, hold-up can still occur, as unforeseen changes in external conditions can result in unexpected shifts in bargaining power (Klein, Crawford and Alchian, 1978).

Information and differences in information between parties are viewed as critical in transactions cost economics. However, misappropriation of shared or transferred information has not been considered. For example, lack of complete information about the environment was identified as a key reason why transactions often had to be uneconomically internalized in the firm:

"Thus, it is bounded rationality in relation to the condition of the environment that occasions the economic problem." (Williamson, 1975, p. 22)

Similarly, the asymmetry of information between parties is viewed as chief source of opportunism risks. Citing Arrow (1971), Williamson writes:

It is generally conceded that if information is asymmetrically distributed between the parties to an exchange, then the exchange is subject to hazards." (Williamson, 1975, p. 31.)

Williamson later describes a specific relationship between information asymmetry and opportunism:

"Opportunism here takes the form of selective disclosure or distortion of the data to which each party uniquely has access. ." (Williamson, 1975, p. 32.)

That is, withholding, not sharing information has been seen as the principal source of risk in interfirm relationships.

Information "assets" in the form of procedures, work practices and training have also been considered a critical source of opportunism risk arising from holdup, principally because of the specificity of these types of assets (Williamson, 1975). However, hold-up arising from information that is specific to a relationship is exactly the opposite of the problem we consider in the study of poaching, where the primary concern is for information that has value outside a relationship. Another perspective on intellectual capability and knowledge work is provided by the literature on the multi-task principal agent problem (e.g., Holmstrom and Milgrom, 1994), which emphasizes the incentive problems that arise because information work and information 
activities cannot be easily monitored or incented. Again, the emphasis of prior literature is on optimal internal use of private information rather than preventing misuse of shared information.

\subsection{Incomplete Contracts and Property Rights Approaches}

More recent and more specialized work by Grossman and Hart (1986), Hart and Moore (1990), and others led to the development of what is generally known as "incomplete contracts theory." These analyses start with the assumption that contracts are incomplete and seek ways to structure the contract such that post-contractual bargaining yields efficient outcomes. Unlike TCE, where the principal concern is that beneficial contracts cannot be written, incomplete contracts places emphasis on ensuring appropriate levels of non-contractible investment in a relationship.

The stylized incomplete contracts model is a setting in which one or both parties to a contract must make a non-contractible investment, which creates value for the entire relationship. Because each party must bear the total cost of their private investment, but only receives a share of the gains they create (simply because there is only $100 \%$ of the relationship value to divide among all parties), they will not provide socially optimal levels of effort. If, however, it is possible to set up an ex-post bargaining structure that allows each firm to capture its fair share of the gains after all investments are made, incentives to invest can be improved. These ex-post bargaining positions are generally established through the ownership ${ }^{2}$ of essential assets. The threat to remove these assets from the relationship creates the bargaining power. Essentially the solution to underinvestment is to create hold-up opportunities to ensure the optimal allocation of bargaining power by assuring that even weak parties can bargain effectively for acceptable returns and thus make non-contractible investments.

\footnotetext{
${ }^{2}$ By "ownership" we are referring to the economists definition of residual rights of control (Hart, 1988). In other words, the owner of an asset retains all decisions regarding the use of the asset that are not already specified by law or contract. The most important of these rights is the right to exclude others from using the asset. Clearly, this notion of ownership is problematic for information (except information protected by some form of intellectual property law, such as a patent or copyright) since it is virtually impossible to exclude someone from access to information they already have.
} 
Grossman and Hart (1986) use this approach to analyze the decision on whether GM should own their metal stamping supplier or utilize arms-length contracting. They conclude that it is in the best interest of GM to own the stamping plant, otherwise the supplier will underinvest in quality, which is a non-contractible investment. Hart and Moore (1988) focus more specifically on the ownership of different combinations of assets within a relationship. They derive some general guidelines for the matching of assets and non-contractible investments. For example, they show that agents that must make non-contractible investments should own the related assets; similarly, agents that need not make non-contractible investments should own no assets. At an extreme, if only one agent must make a non-contractible investment, they should own all the assets.

The incomplete contracts approach has been extended to the study of information assets by Brynjolfsson (1994). He considers a setting where production within a firm (or among a specified set of firms) requires the use of physical and information assets. He studies the conditions under which information assets should be transferred and when ownership of physical assets should follow the ownership of information assets. In general, if an agent must make a non-contractible investment, or has essential information, then welfare is maximized when that agent also owns the complementary physical assets. Alternatively, essential information can be transferred to agents that must make non-contractible investments. A similar framework was utilized by VanAlstyne, Brynjolfsson and Madnick (1994) for analyzing who should own databases, and by Richmond and Seidmann (1992) for evaluating outsourcing contracts. As we shall show, this work deals principally with aligning incentives to reduce shirking, but the mechanisms used to control this risk are ineffective, even counter-productive to control poaching, even in the same outsourcing domains addressed in this literature.

While this more recent literature creates the precedent for considering the role of information assets, the focus is again on optimizing production in a bargaining group of limited scope (such as a firm or a buyer-supplier pair). That is, it is primarily concerned with underinvestment and holdup. We consider the very different problem of deliberate misuse of an asset. These problems arise in situations where not all parties are able to simultaneously bargain over the allocation of 
the information, ${ }^{3}$ the parties that might value the information are unknown at the time of contracting, or contracts that specify the optimal allocation and limits to use of information assets are not enforceable.

\subsection{Summary and Comparison of Previous Literature}

Overall, while the importance of various types of information - about the environment, performance, capabilities, or intentions of the various parties, or specific information such as training that is critical to executing a task - plays a central role in many previous theories of contracting, there has been little attention to the potential misuse of information in a contractual relationship and virtually no analysis of the risks created by information that is shared or obtained as a by-product of a contractual agreement.

\section{A Theory of Poaching}

\subsection{Introduction}

We define poaching ${ }^{4}$ as involving three components:

1. The exchange of information between two parties, as a natural byproduct of contractual exchange for other goods or services, necessary for the performance of contractual obligation.

2. And the subsequent use of this information by the receiving party, outside the purposes for which the information was provided, and for its own benefit or economic gain

\footnotetext{
${ }^{3}$ For example, one of the relevant parties might be a direct competitor of the firm engaged in supplier negotiations.

${ }^{4}$ Our review of the economics and management literature revealed only two current uses of the phrase "poaching". The first appears primarily in development economics and refers to the unlawful hunting of endangered species. The second reference appears in the labor economics literature and refers to the common practice of hiring staff from competing firms. While this second definition shares some similarity to our analysis, the concern in that literature is primarily the transaction costs of replacing the employees and the loss of capabilities rather than the transfer of specific intellectual assets. We therefore believe that our use of the term is both new, distinct and unlikely to be confused with references in the prior literature.
} 


\section{At the expense of, or creating economic damage to, the party that provided the} information.

For poaching to have substantive economic implications, all three components must be present. Clearly, absent information transfer (1) there is no issue to consider. The second condition restricts the analysis to information that has value either in reuse or resale, limiting the analysis and distinguishing this theory from other theories of the allocation of information assets which consider only parties and activities relating to a current contract. Finally, without economic damage to the contributing party there is no economic concern, since reuse of information (absent damage) is always beneficial to society.

It may be helpful to put this in the context of previous mainstream work in contracting. TCE deals with the risk of shirking, or the under-provision of effort (either commitment of labor or of capital as factors of production) or of hold-up (the misappropriation of compensation for or economic gain from exchange). Incomplete contracts theory deals with the risk of insufficient non-contractible investment (a form of shirking) and the role of property rights in promoting optimal investment. Poaching deals with the misappropriation of information, a factor of production that is not consumed by its use, and is difficult or impossible to return.

We believe that this provides a natural extension to existing work in TCE, but one that would not have been considered at the time that Williamson and KCA were writing, because it was less relevant. That is, the idea of a factor of production that could be costlessly replicated, reused without cost, and yet risky to transfer would have seemed implausible. Moreover, given the nature of exchange in the heavily integrated firms of the era, and the nature of goods and services exchanged, the risks of information transfer as creating contractual risk would likewise have seemed implausible.

Perhaps more importantly, while representing a natural extension to TCE, the use of the concept of poaching will on occasion lead to a very different understanding of risk profiles and a more complete and more accurate prediction of risks associated with contractual exchange. We begin 
this discussion by analyzing a series of case examples that describe how poaching can appear and consider the remedies that can be taken to avoid these poaching problems. We then investigate standard contractual remedies that have been applied to other types of contracting problems, and evaluate their performance in limiting poaching. These examples will be treated more formally in a model presented in Section 4.

\subsection{Case Examples}

Poaching is a relevant concern in a wide variety of settings, including both manufacturing and services, and in a variety of activities that can be outsourced. The case examples below represent events and scenarios faced at actual firms, although in some cases the names are omitted for confidentiality:

Example 1 (dual sourcing): A common practice in the semiconductor industry is a "dual sourcing" arrangement, where a company licenses technology to a competitor to enable them to produce competing products in return for a royalty. The goal of these arrangements is to allay customers' fears of hold-up by the principal manufacturer and ensure a stable supply of compatible products, which promotes greater adoption. In 1982, Intel Corporation licensed the technologies related to the 8086 microprocessor to Advanced Micro Devices (AMD) as part of a long-term technology sharing and dual sourcing arrangement. By 1986, Intel decided that they no longer wanted AMD to be the second source, starting with the 80386 microprocessor line. However, using the knowledge and technologies they previously obtained and realizing that Intel was not going to continue the relationship, AMD reverse engineered Intel's 80386 microprocessor and soon had a competing product in the market. ${ }^{5}$ AMD subsequently developed their own competing technologies and has now become a fierce competitor of Intel in microprocessors, sometimes beating Intel to market with next generation microprocessor technology.

\footnotetext{
${ }^{5}$ AMD was retroactively granted rights to the 80386 processor technologies in an arbitration proceeding, later upheld by the US Court of Appeals Ninth Circuit (Intel Corporation v. Advanced Micro Devices, No. 92-16899), due to Intel's breach of the original dual sourcing arrangement.
} 
Example 2 (technology-based services): Use of a third-party account administration firm naturally requires that an insurance company using this service provide all of their company records on individual accounts so that the account administrators can process and service accounts. The account administration firm now has the ability to mine the company data to identify the most profitable customers, which they can pass on as sales leads to competitors or resell to third-party marketing firms. At a minimum, this could cause a loss of business. In addition, it could also cause substantial reputational damage to the insurance company if their customers discovered that their private information, entrusted to the insurer, was being made freely available to other firms without their consent.

Example 3 (information technology contracting): A credit card firm engages a systems development consultant to build an extensive database system for correlating private product use information with publicly available customer data. The goal is to identify the predictors of profitable customers and to enable rapid design of new financial services products. After constructing the system, the systems consultant has considerable expertise in building data warehousing systems in credit cards and has fully tested source code for interfacing credit card databases with external data sources. They are now in a strong position to underbid their competitors for work at other credit card firms by reusing expertise and possibly actual code from their previous engagement. They may have even factored in the value of learning and transferable expertise in their original bid for the job. More damaging to their original client, the consulting firm can pitch this work to competing credit card companies, and with the expertise acquired during their first implementation can enable these firms to successfully implement "copycat" technologies years before they otherwise would have been able to do so. This accelerated entry of competitors and their rapid deployment of similar technologies will shorten the period of advantage enjoyed by the original client firm.

Example 4 (business services): Big Fish (BF), a large domestic travel agent seeking to compete with global firms such as American Express, needs to have expertise and presence in adjacent or related markets like Canada and the UK, and it needs them immediately. It lacks the expertise to 
understand the travel alternatives available in these markets, and it lacks the local presence to receive priority allocations (e.g., rooms during Wimbledon tournaments) or preferred pricing from local suppliers. It forms an alliance with Little Fish (LF), a specialized player in one of these markets. The local affiliate, Little Fish, is interested in obtaining access to Big Fish's global communications network, software for client support, and negotiations skills and preferred pricing from global carriers and international suppliers of travel services. After two or three years, when it has the local expertise it needs, the local market share it needs, and the local off-shore name recognition among clients and providers of travel-related services for these clients, Big Fish opens its own offices, in the same building as Little Fish, and in direct competition with Little Fish. It is willing to honor the other terms of its agreement with Little Fish, but as LF's customers are deserting it and transferring to $\mathrm{BF}$, this offers little consolation to its former partner. BF has appropriated the expertise and exposure it gained through cooperation, and is now competing effectively with LF.

LF soon recognizes that it does not have the resources to survive direct competition with BF in the long term. It contacts a major competitor of Big Fish, and offers to transfer the expertise and software that it has received during its period of affiliation with $\mathrm{BF}$, potentially undercutting some of BF's sources of competitive advantage.

Example 5 (consultants). Here $\mathrm{BF}^{6}$ engages a major strategic consulting house to help it develop a strategy and systems infrastructure for offering different prices to different consumers for travel services. This project involves the development of a database infrastructure for customer information, the development and validation of a variety of modeling tools to determine customers' willingness to pay, and the design of systems that monitor the marketplace to assess the customers' next best alternatives. In order to provide strategic consulting services, the firm must first learn a great deal about BF's business and the environment in which it operates, the various strategies that $\mathrm{BF}$ has considered, and the resources needed to implement them. It will need to learn a great deal about customer behavior in purchasing travel services, the predictors of

\footnotetext{
${ }^{6}$ This event occurred at different firms in the same industry as in example 4. The same pseudonyms are retained to shorten the exposition.
} 
customer profitability, and integrating external data sources necessary to drive these predictive models. It then consults for and develops a price discrimination strategy companies in different aspects of the travel business, such as Marriott and USAirways, two companies that are not competitors but that are critical suppliers to BF. It then consults for and develops a price discrimination strategy for other firms that can utilize differential pricing such as CitiBank or Prudential Insurance, companies that are neither competitors nor suppliers.

\subsection{Analysis of Examples}

In each of these cases we observe the essential ingredients for poaching: information transfer, opportunity for reuse of transferred information, and damage to the original contributor of the information. We also observe several of the factors that make poaching more likely:

1) Weak intellectual property protection. The first example the inability to "return" information at the end of a contractual relationship. The other examples highlight the difficulties created by limited or non-existing protection for expertise or business practices. Had suitable intellectual property protection been in place, there would have been legal remedies to reduce the potential for poaching.

2) Existence of complementary assets. In all cases, the firm engaged in poaching has a well defined market of firms that had the complementary physical and information assets to exploit the information. In some cases (e.g., Example 1) the contract could only be written with a firm that already enjoyed or was able to build complementary facilities. In other cases, there were competitors with similar capabilities that could attain parity or advantage by using the poached information. Poaching is less of a threat absent these complementary assets. For example, the firm described in Example 3 breaks most projects down into multiple parts and assigns them to different systems development contractors. That reduces the possibility that a single contractor will have all the expertise required to reconstruct the entire system. 
3) Bounded Rationality: Limited observability. In many cases, even when remedies could exist, the actual poaching is difficult to observe. In the insurance example, it would be difficult to know whether the account administrator was reselling data with any certainty unless steps were taken to mitigate this specific risk.

4) Bounded Rationality: Limited predictability. Even in cases where the poaching is readily observable, it may not have been anticipated and therefore was not prohibited in the contract. For example, in Example 4 it may have been difficult for LittleFish to realize that BigFish would have all the necessary resources to enter into their market after such a short period of time. It might be difficult for the credit card company in Example 3 to anticipate all the potential uses for their target marketing technology in other industries or the types of firms that might seek to offer credit cards in the future along with their existing portfolio of products or services.

Analysis of the social welfare implications of poaching in these examples is somewhat more difficult. Despite being privately detrimental to the provider of the information, most of these cases lead to increases in total social welfare, provided that the risk of poaching is not so great that firms refuse to engage in trade altogether. When trade occurs, in almost all cases, ex-post social welfare is increased because the replication and reuse of information has virtually no incremental cost, but leads to increased market efficiency or decreased production cost for other parties.

However, the distribution of value from poaching is somewhat unusual. While the firm that has lost control over a valuable productive information asset as a result of poaching is never better off, and almost always strictly worse off, as a result of this poaching, the distribution of benefits among the other parties is more complex.

The party that misappropriated and misused the information asset will either use the asset directly if it can, sell it to a third party, or enter into an alliance, venture or licensing agreement with a third party if this is the preferred way to exploit the asset. This exploitation of the asset will 
increase competition with the first party, the information provider, creating gain for end users/customers of the goods or services enabled by the original information asset.

When the second party's gain exceeds the first party's loss there should be no difficulty in envisioning a contract that actually permits the reuse of information. That is, for financial payment from the second party to the first, the second party gains specific rights to reuse the information, independently or with specified partners. When the second party's gain is less than the damage caused to the first party, however, drafting a contract to permit the reuse of information should be infeasible; that is, the payment that the first party would demand would exceed the value that the second party would expect to capture.

In general, poaching leads to increased social welfare either by enabling production in markets that were not previously served, by increasing competition, or by lowering production cost. As a result, it is often not the case that efforts undertaken by Firm 1 to restrict poaching are socially beneficial. $^{7}$

\subsection{Comparison to TCE Analysis}

In distinguishing the differences that a theory of poaching implies for contractual design and post contractual conduct, it is useful to compare the predictions of traditional transactions cost economics approaches to the predictions yielded by our theory of poaching. In almost every example, transactions cost or contract theory analyses of these cases would highlight different concerns. More importantly, in most cases, analysis of poaching would lead to different contractual remedies and in some situations generate contradictory conclusions about the suitability of various contractual structures.

In Example 1, transactions cost analysis would highlight the potential for hold-up as one party, through relationship specific investment, has developed a dependence on the other. The principal

\footnotetext{
${ }^{7}$ There is, of course, the classic problem with intellectual property protection that it is necessary ex-ante for the optimal production of intellectual property, but typically inefficient ex-post.
} 
risk to Intel would be hold-up from having made a commitment to a single alternative source during the duration of the relationship. The traditional TCE remedy would be to have the primary supplier contract with several vendors, yet from the perspective of poaching this may be the worst possible remedy. The likelihood of poaching increases at least linearly with the number of independent suppliers, simply because there are more opportunities for players independently to choose to abuse their counterparties; however, the likelihood of poaching will also increase more rapidly, as each secondary supplier perceives the possibility that other suppliers will poach and experiences competitive pressures to do so as a result or at a minimum, recognizes that it would be increasingly difficult to attribute the losses resulting from poaching to a specific supplier when the supplier base is large.

In the second example, a primary concern raised by TCE analysis would be the hold-up of the client, since switching third party administrators would require substantial time and cost to the insurance company. However, perhaps more severe is the risk of shirking in the customer service function, which could cause customer attrition at the insurance company and reduce profitability. Given that customer service outcomes could be monitored through satisfaction surveys, measured complaint and error rates, or inspection of actual customer service events, ${ }^{8}$ there is an opportunity for incentive contracting. However, if incentive contracting also comes with a commitment to full information sharing between the client and vendor or product problems, customer service concerns or other proprietary data, then this can increase the scope of poaching. Thus, these contractual remedies, at best, do nothing to reduce poaching and at worst, may actually increase it.

In the third and fifth examples (software development outsourcing), there is often a substantial gain from trade resulting from using a specialized development house for software production. A traditional TCE analysis would suggest that the principal risk to the client comes from vendor shirking; given the difficulty of monitoring vendor performance and the difficulty of measuring

\footnotetext{
${ }^{8}$ It is not uncommon in customer service call centers to have one hour out of every 40 hours of telephone time for each representative monitored by a supervisor or tape recorded, and evaluated against a set of customer service guidelines. Most customer support centers also allow random monitoring of phone calls by supervisors or client personnel.
} 
output (quality of software is not apparent except over very long time periods), combined with the difficulty of writing a complete and detailed contract for future delivery of a product whose requirements will not be fully known until some later time, shirking does indeed appear to pose considerable risks. Secondarily, to the extent that the client becomes dependent upon the vendor for delivery, maintenance, and operation of mission critical software, holdup by the vendor becomes a real possibility as well. In this case, since incentive contracting is limited to coarse measures such as time of delivery, the principal remedy for shirking would be for the client to work closely with the vendor, transferring expertise and assuring quality of the delivered product. However, if as we have claimed, the principal risk is from poaching, then once again this remedy may assure that the developed product is of sufficient quality to permit resale and thus may actually have the unintended effect of facilitating poaching.

Interestingly, like much of the literature on the "make vs. buy" decision, research on IT contracting has placed substantial emphasis on the tradeoff between cost savings and vendor shirking as the explanation for uneconomic vertical integration. An analysis of poaching, however, would suggest that a more serious concern should be misuse of information. In addition, this sort of analysis of poaching is different than the usual remedy of "not outsourcing strategic systems" (see e.g. Lacity, Willcocks and Feeny, 1996) or never outsourcing "core competencies" (Quinn and Hilmer, 1994), since it does not rely on definitions of "core" or "strategic", but identifies an issue that is present whenever transferred information has value from reuse or resale.

A traditional TCE analysis of the fourth example would show BF enjoying critical resources (integrated information systems, a global network, and a global set of relationships with international suppliers) that are not readily available to LF elsewhere; this suggests that LF will face a small numbers bargaining situation and if it makes commitments to its clients to deliver global services it will be vulnerable to holdup by BF. In contrast, BF would conclude that LF had few critical resources, and that any of several local agencies might provide it with comparable service; holdup by LF would not be a threat. Thus, both BF and LF might conclude that, provided that each could monitor the degree of effort made by the other, the principal risk 
associated with the relationship would stem from LF's reliance upon BF. This risk might manifest itself as changes in payments between $\mathrm{BF}$ and $\mathrm{LF}$, or disputes over distribution of gains resulting from their association. This would be made more complex by the unobservability of some of these gains; how, for example, might each party estimate the increase in revenues earned by the other that were directly attributable to their relationship? Classical approaches to resolve these problems might, if profits from the association could be measured, result in some form of long term incentive contract. If monitoring were not sufficiently effective, some form of asset transfer to LF might be appropriate to help balance long term bargaining power. However, incentive contracting will do little to prevent poaching, and asset transfers to prevent shirking always increase the danger of poaching.

\section{A Model of Poaching}

In this section we present a model of poaching that describes contractual outcomes in scenarios similar to those described in the "Case Examples" in Section 3.2. Our model assumes that poaching of an information asset is possible and focuses on the effects of complementary assets and competition in determining the profit and social welfare implications of poaching.

\subsection{Model Setup}

Consider the following production situation. There are three classes of assets:

$I-$ An information asset

$P$ - A production plant, which is indivisible

$D$ - A distribution system, which represents coverage of a sales territory. Each firm (i) has a distribution territory (which may be empty or overlap other regions) represented by $D_{i}$.

These assets are all fixed and, moreover, cannot be acquired through investment over the time horizon of this model. Assets $P$ and $D$ are also non-transferable, while I is transferable and can be possessed by multiple firms.

There are three firms: 
Firm 1 - A "product innovator" who owns $D_{l}$ and possesses $I$

Firm 2 - A "contract manufacturer" who owns $P$, but initially has no distribution $\left(D_{2}=\varnothing\right)$

Firm 3 - A "fast follower" who has access to a distribution system $D_{3}$

The unit cost of production $(c)$ is determined by the ownership of physical and information assets (the notation we will use is $c(A)$ where $A$ represents a set of assets owned by a coalition of firms). We assume that no production is possible without information $(I)$, and that access to the production plant $(P)$ makes production more efficient. Thus,

$$
c(\{I, P\})<c(\{I\})<c(\{\varnothing\})=\infty
$$

For notational simplicity we define $c^{p}=c(\{I, P\})$ and $c^{I}=c(\{I\})$.

As stated earlier, distribution systems represent a sales territory. We describe a sales territory as a number of customers $(T)$ in that territory, each with unit demand (one unit or none) and a reservation price $\bar{r}$ for the good common across all consumers and regions. Given that there are two non-empty distribution regions, there are only three possible sales territories to consider, one unique to each distribution system $\left(T_{1}, T_{3}\right)$, and one region that overlaps between the two $\left(T_{13}\right){ }^{9}$ These territories are distinct in the sense that customers in one territory are assumed to not purchase products in another territory.

When more than one firm produces and sells product in a region, we assume they set price simultaneously and non-cooperatively. We model competition in these regions using the well known "linear city" model of Hotelling (1929). We chose this approach because it represents the simplest and most tractable model that captures the notion that competition does not necessarily lead to Bertrand pricing because of firm differentiation. Following standard assumptions, we assume that customers in a territory (T) are uniformly distributed along a line of unit length with location $x(x \in[0,1])$ and face a quadratic "transportation cost" given by $t x^{2}$ for a firm located at the origin and $t(1-x)^{2}$ for a firm located at position 1 . This transportation cost can be thought of as a degree of differentiation of the firms, which can arise due to brand, advertising, or other factors. As t increases, the firms are increasingly differentiated and eventually act as monopolies

\footnotetext{
${ }^{9} \mathrm{D}_{1}$ corresponds to territories $\mathrm{T}_{13}$ and $\mathrm{T}_{1} ; \mathrm{D}_{3}$ corresponds to territories $\mathrm{T}_{3}$ and $\mathrm{T}_{13}$.
} 
over the customers in their region. When $\mathrm{t}=0$, there is no differentiation and Bertrand competition will ensue. To avoid issues of whether the entire market will be served due to these transportation costs, we assume that it is always economically beneficial to serve the entire market if it is economical to serve anyone [a sufficient condition is $\bar{r}>\frac{3}{2} t+\max \left(\left\{c_{i}\right\}\right)$ where $\left\{c_{i}\right\}$ is the set of unit costs for the set of firms selling in that region - see appendix for proof]. Note that in our model, no more than two firms compete in any market and since it has been previously shown that optimal location of two firms in the linear city model are at the ends of the line (see Tirole, 1998, p. 280) we need not consider the optimal location problem of these competing firms. We also make the further assumption that firms can only offer a single price and cannot price discriminate by location $(x)$. In the discussion that follows we let $p_{1}^{m}, q_{1}^{m}$ represent firm 1's prices and quantities in a monopoly setting and $p_{1}^{d}, q_{1}^{d}$ represent prices and quantities in a duopoly setting (for duopoly, $p_{3}^{d}, q_{3}^{d}$ are defined analogously for Firm 3).

Under these competitive assumptions, we can define two prices that will prevail depending on whether a territory is served as a monopoly or duopoly. Since our earlier assumption guarantees that any market that is served is served completely, the optimal monopoly price takes full surplus from the most distant customer, and this price is maximized when the monopolist locates at $\mathrm{X}=1 / 2$. Therefore the monopoly price is $p^{m}=\bar{r}-t / 4$, and the firm receives the entire demand in that region $q^{m}=1$ (we let q represent the fraction of a territory that is served - total demand is Tq where $\mathrm{T}$ is the territory size defined above).

For duopoly competition it is easy to show (see Appendix for proof) that for firm $i$ (when competing with firm $j$ ) prices and quantities are given by:

$$
p_{i}^{d}=t+\frac{c_{i}+2 c_{j}}{3}(2) \text { and } q_{i}^{d}=\frac{1}{2}-\frac{c_{i}-c_{j}}{6 t}
$$


That is, they split the market depending on their relative cost advantage. If unit costs are identical $\left(c_{i}=c_{j}\right)$, these equations reduce to $p^{d}=c+t$ and $q^{d}=\frac{1}{2}$ for both firms. Note that with our assumptions about market coverage above, these solutions guarantee that duopoly prices are lower than monopoly prices $\left(p^{d} \leq p^{m}\right)$.

Our analysis will involve the comparison of different outcomes depending on the distribution of the various assets, especially the information asset which can be redistributed and utilized by firms other than Firm 1 by poaching or by contractual agreement. To determine how surplus is distributed when firms bargain with each other, we use the Shapley Value (Shapley, 1953). The Shapley Value for a firm is derived as the difference between the value a coalition receives when the firm is present (and thus contributes the use of the assets they own) and the value it receives when the firm is absent (thus possibly excluding firms from using their assets). This is averaged over all possible coalitions of firms engaged in bargaining. The Shapley Value is chosen because it yields a non-arbitrary division of surplus, captures the intuitive idea that bargaining power should be proportional to marginal creation of value, and is commonly used in incomplete contract modeling (see e.g., Hart and Moore, 1990 or Brynjolfsson, 1994). In its simplest form (two firms, both essential to production) it reduces to the Nash bargaining solution where the two firms simply divide the bargaining surplus equally.

We now consider several possible cases that represent different production outcomes in various poaching scenarios. We will use the notation $V_{i}$ to represent the value contributed to total surplus by firm $i$, and $\pi_{\mathrm{i}}$ represent the total profit captured by firm $i$ (their share after bargaining).

\section{$\underline{4.2}$ Poaching Analysis}

As a baseline, we first calculate the profits of Firm 1 when they choose not to contract with Firm 2 and no third-party (Firm 3) exists. Firm 1 enjoys a monopoly in all regions where they have distribution capability. The profits are therefore: $\pi_{1}=V_{1}=\left[p^{m}-c^{I}\right]\left(T_{1}+T_{13}\right)$ and represents the 
default outcome. Firm 1 faces no poaching risk, but similarly produces inefficiently because they have no access to the plant so are forced to product at a cost $c^{I}$ where $c^{I}>c^{P}$.

If poaching were not possible, Firm 1 could contract for Firm 2 for production capacity which would lower marginal production cost to $c^{P}$ and total production costs to $c^{P}\left(T_{1}+T_{13}\right)$. As both firms are essential to realizing this cost savings, bargaining would evenly divide this surplus among the two firms yielding the following profits:

$$
\begin{aligned}
& \pi_{1}=\left(p^{m}-\frac{c^{I}+c^{P}}{2}\right)\left(T_{1}+T_{13}\right) \\
& \pi_{2}=\frac{1}{2}\left(c^{P}-c^{I}\right)\left(T_{1}+T_{13}\right)
\end{aligned}
$$

As long as Firm 2 has no access to distribution capability or no resale opportunity, this result will prevail and Firm 1 can realize gains from outsourcing. However, if Firm 2 should obtain access to distribution capability, the outcomes will change dramatically. The simplest story is that Firm 2 enters into an agreement with Firm 3 to obtain distribution capability and poach the information asset $(I)$ from Firm 1, unbeknownst to Firm 1. ${ }^{10}$ This will have two negative effects on Firm 1. First, they will overestimate the potential cost savings for contracting with Firm 2 because they believe that they will have a monopoly in the overlapping region, when in fact they will be facing a competitor. This will lead them to misestimate their bargaining position with Firm 2 and overpay for access to the plant. ${ }^{11}$ Second, they face the first order loss in profits from facing a competitor in the overlapping region. The profits for Firm 1 are given by:

\footnotetext{
${ }^{10}$ An alternative story is that Firm 2 acquires distribution capability equivalent to Firm 1 during the lifetime of the production agreement. Once intellectual property protection expires, Firm 2 is now a cost advantaged competitor to Firm 1 in their home territory. At a minimum, this will create a shift to duopoly competition. In the worst case, Firm 2 is sufficiently cost advantaged over Firm 1 that they can price Firm 1 out of the market. This can occur if: $\frac{c^{I}-c^{P}}{6 t} \geq \frac{1}{2}$ and Firm 1 has no alternative cost lowering technology or partnership available (this can be derived by using the heterogeneous cost equations and finding the cost difference that sets Firm 1's duopoly demand to zero). This corresponds to the situation described in Case Example 1.

${ }^{11}$ There are two additional assumptions that we will use in calculating damages in this and subsequent scenarios. First, choice of location is costless and can be made after the firm discovers whether there is a monopoly or duopoly in a region. This is not restrictive, as it just represents a transfer from firm 1 if "moving" is costly and a
} 


$$
\begin{aligned}
& \pi_{1}=\left[p^{m}-c^{P}\right] T_{1}+\left[p^{d}-c^{P}\right] q^{d} T_{13}-W \\
& W=\frac{1}{2}\left[c^{I}+c^{P}\right]\left(T_{1}+T_{13}\right)
\end{aligned}
$$

Where $\mathrm{W}$ represents the payment to Firm 2 for access to the plant. In the bargaining game between Firms 2 and 3, both firms are essential - Firm 2 cannot produce without distribution, and Firm 3 cannot obtain product without Firm 2. Therefore, they split the profits earned from poaching (and Firm 2 earns their profit from serving Firm 1 as well):

$\pi_{2}=\frac{1}{2}\left(p^{m}-c^{P}\right) T_{3}+\frac{1}{2}\left(p^{d}-c^{P}\right) q^{d} T_{13}+W$

$\pi_{3}=\frac{1}{2}\left(p^{m}-c^{P}\right) T_{3}+\frac{1}{2}\left(p^{d}-c^{P}\right) q^{d} T_{13}$

The change in profits by poaching for each firm can be calculated by comparing the profit functions for Case 1 and Case 2 (aggregating the profit calculations for firm 2):

$$
\begin{aligned}
& \Delta \pi_{1}=-\left(p^{m}-p^{d} q^{d}+c^{p} q^{d}\right) T_{13}=-\left(\bar{r}-\frac{3}{4} t\right) T_{13} \\
& \Delta \pi_{2}=\frac{1}{2}\left[T_{3}\left(p^{m}-c^{p}\right)+T_{13}\left(p^{d}-c^{p}\right) q^{d}\right]=\frac{1}{2} T_{3}\left[\bar{r}-\frac{t}{4}-c^{p}\right]+\frac{1}{2} T_{13} t \quad(7 \mathrm{a}-7 \mathrm{c}) \\
& \Delta \pi_{3}=\Delta \pi_{2}
\end{aligned}
$$

Equations $7 \mathrm{a}-7 \mathrm{c}$ can now be used to calculate the optimal outsourcing decision for Firm 1 as well as the profit implications of outsourcing when poaching is a risk.

The outsourcing decision for Firm 1 depends on whether the gains from production efficiency outweigh the losses either from poaching or the cost of remediation. Let the fixed cost of remediation be represented by $R$. These costs represent a fixed investment in contractual safeguards - these could include monitoring costs, contractual restrictions on the vendor or the client which create opportunity costs, or other losses incurred from implementing the remediation strategies described earlier in Sections 3.5 and 3.6. For remediation to be viable two conditions rather than a lump sum for total production in their outsourcing contract for Firm 2. Again, if this is not true, it simply represents a transfer from Firm 1 to Firm 2. 
must be satisfied. First, remediation cannot be viable if it exceeds the gains from outsourcing which implies a condition: $\left(T_{1}+T_{13}\right)\left(c^{I}-c^{p}\right)<R$. Second, the cost to Firm 1 of remediation must be less than the losses from poaching. Because bargaining between Firm 1 and Firm 2 yields equal surplus division, Firm 1 will privately bear half of the remediation cost. Thus, remediation can be beneficial if $\left(\bar{r}-\frac{3}{4} t\right) T_{13}>\frac{R}{2}$. If these two conditions both hold, then the firm will optimally outsource and invest in remediation. If either of these conditions do not hold, then the firm faces a simple outsource vs. insource decision depending on whether gains from trade (net of poaching losses) are positive. Thus a firm will outsource when: $\frac{1}{2}\left(T_{1}+T_{13}\right)\left(c^{I}-c^{p}\right)<\left(\bar{r}-\frac{3}{4} t\right) T_{13}$.

Where the costs of remediation are prohibitive and that the firm chooses to outsource anyway either because they ignore or miscalculate the poaching risk, or that outsourcing is still profitable even with poaching -- it is now straightforward to calculate the change in profit due to poaching. This is useful for examining the profit implications of poaching, which in some determine the strength of incentives to poach and well as the prospects for viable outsourcing arrangements.

Several observations are apparent from the results in Equation 7a-7c:

1) The loss from poaching to Firm 1 is: i) increasing in the size of the overlapping region, ii) increasing in customers reservation price, and iii) decreasing in the degree of product differentiation (that is $\left.\frac{\partial \Delta \pi_{1}}{\partial t} \leq 0\right)$.

2) Poaching is only profit-neutral for Firm 1 if there is no overlap in distribution capability $\left(T_{13}=0\right)$. In this case poaching is pareto-optimal because it opens the new market $\left(T_{3}\right)$, but one could argue that Firm 1 receives less than their "fair" share of the surplus since the value of the information used in region $T_{3}$ accrues entirely to Firms 2 and 3.

3) The profits of Firms 2 and 3 are always weakly improved with poaching. They are strictly improved if market $T_{3}$ can be served by a monopolist, or if market $T_{13}$ has profits in the duopoly case. They are increasing in the degree of differentiation between the products offered between Firm 1 and Firm 3 as long as region 3 is at substantially larger (at least 
four times under our assumptions) the size of the overlapping region and strictly increasing in the size of the distribution territory served by Firm 3 (which can be interpretated as a quantity of assets complementary to the information asset).

4) Consumer surplus is never decreased by poaching in these examples. Consumers receive weakly lower prices in the overlapping region and the possibility of realizing positive surplus in region $T_{3}$.

These results from our simple model describe very neatly the situations faced in the earlier case examples. In each of the Case Examples 1-4 in Section 3.2, there was a situation where an information asset that was provided to a third party for efficiency reasons, could be transferred to another firm, whose presence in the market caused damage to the firm that contributed the asset. These all correspond to cases where products are substitutable and there is overlap in distribution in our model (that is, $T_{13}>0$ ). In some cases, such as the data processor poaching customer information (Example 2), the overlapping region is less than the total market but has no market expanding effect $\left(T_{1}>0, T_{13}>0, T_{3}=0\right)$. In other cases such as those described in Examples 3 and 4 , the overlapping region was essentially the entire market $\left(T_{1}=0, T_{13}>0, T_{3}=0\right)$. In all these examples, Firms 2 and 3 and consumers are better off, while Firm 1 is generally worse off.

In Case Example 5, there are actually multiple scenarios that can be restated in our model formulation. Recall that Case Example 5 described a situation where a travel agent (BF) engages a strategic consulting firm to aid in strategy formulation. This strategy proves to be useful for direct competitors, suppliers and firms in unrelated markets. In the direct competitor case, this is an extreme form of the poaching case described where the total market is primarily comprised of the overlapping region $\left(T_{13}>0, p^{d}<p^{m}\right.$ but also $T_{1}$ and $T_{3}$ small). In this case, the intermediary (consultant) gains benefits from the initial engagement with BF, and then recaptures some of BFs gains from the relationship by passing the information on to competitors. The primary winner is the firm that engaged in poaching, $\mathrm{BF}$ is substantially worse off, and the competitor is slightly better off. 
In the second scenario in Example 5, where information is resold to suppliers (airlines), this is a situation where the overlapping region $\left(T_{13}\right)$ is non-null, but there is also a substantial outside region $\left(T_{3}\right)$-- which is possibly much larger than the region served by Firm 1 . In this case, both producer and consumer surplus are increasing overall. Firms 2 and 3 gain at the expense of Firm 1. This scenario represents a bargaining opportunity between Firm 1 and Firm 2 to achieve this social optimum, although anti-trust or collusion concerns might limit the chances that such an agreement could be reached.

In the final scenario, poaching to benefit non-competitors, this is the ideal situation from Firm 1's standpoint. There is no overlap in distribution region $\left(T_{13}=0\right)$ and therefore no damage to Firm 1. Poaching is socially efficient as Firms 2 and 3 benefit. ${ }^{12}$ The only concern in this analysis is that Firm 1 has not been able to capture the secondary value that their information has brought to the market by enabling region $T_{3}$ to be served. This could be accommodated by reducing the consulting fees paid by Firm 1, or if large enough, by a significant licensing fee split between Firm 1 and Firm 2. This, of course, assumes that Firm 1 either anticipated the potential for poaching or could detect it after the fact.

\subsection{Resolving Poaching Problems through Bargaining}

The preceding section assumed that reducing poaching was an all or nothing proposition - Firm 1 could either invest in detection or insource, but was assumed not to be able to participate in the potential social gains from information reuse. There are several situations where this might be too stringent. First, the firm may be able to make a precontractual investment in identifying alternative uses for the information asset. This information could form the basis of a profit sharing agreement between Firm 1 and Firm 2 allowing information reuse. In some cases, the alternative uses may already be known. Another case is when Firms 1 and 2 engage in a long term relational contract where reuse can be negotiated as opportunities arise. The presence of

\footnotetext{
${ }^{12}$ Note that some interpretations of this situation could violate the third condition in our definition of poaching that for theft of an asset to be poaching it has to create damage to the part that contributed to the asset. However, this is consistent if we view the profits from Firm 2 as belonging to Firm 1.
} 
this bargaining opportunity expands the range of the parameter space for which outsourcing is viable, and also creates gains in consumer surplus because it opens new markets and increases competition in the overlapping market. As the "owner" of the information asset I, Firm 1 will only participate if they can recover their losses, which is also the condition where total change in producer surplus is positive. This occurs when:

$\Delta \pi_{2}+\Delta \pi_{3} \geq-\Delta \pi_{1}$

Substituting solutions found earlier and rearranging this equation yields:

$\frac{T_{3}}{T_{13}} \geq \frac{\left(4 \bar{r}-t-4 c^{I}\right)}{4 \bar{r}-7 t}$

This suggests that a negotiated agreement to allow information reuse is more likely to be possible when the demand in the outside monopoly market is large compared to the overlap or products are more differentiated (which implies less loss from duopoly production).

However, in many cases it may difficult to reach such an agreement. First, this type of agreement could be perceived as collusive by regulators. Second, it relies on the ability of Firm 1 to preidentify all firms that have potential reuse opportunities. Thus, we expect that negotiation alone will have limited efficacy; we consider alternative approaches in the next section.

\section{Remedies for Poaching}

We begin by examining the extent to which common remedies for other transaction risks can reduce or prevent poaching. Then we examine approaches for managing risks that are unique to poaching.

\subsection{Existing Approaches}

There are a wide variety of contractual remedies for addressing various types of information or incentive problems that have been identified by other contracting theories. In this section, we systematically examine the efficacy of these approaches for limiting poaching, as well as any negative consequences that could arise when these approaches are employed without considering 
the potential for poaching. As we saw repeatedly in the previous section, the general conclusion is that most traditional remedies have limited ability to address poaching, and a few can be directly counterproductive. At the end of this section, we identify several new mechanisms that appear to resolve some types of poaching issues.

\subsubsection{Incentive Contracting and Monitoring}

The classic solution to incentive problems is to propose a contract that aligns the interests of the client and the vendor. The general structure is that when effort is not observable directly, the client can be compensated on the basis of an ex-post signal of effort (such as output, stock price, etc.). This partial alignment of incentives leads to increased effort by the vendor. However, the more random variance in the signal, the more unnecessary risk that is placed on the agent from incentive contracting and thus, less weight can be placed on the signal. Investments in monitoring can improve the precision of the signal, at some expense. This is the classic tradeoff between incentives, risk, and monitoring cost (see Holmstrom and Milgrom, 1994).

Incentive contracting is only weakly applicable to preventing poaching because poaching is difficult to observe (and thus difficult to disincent). To the extent that poaching does affect highlevel performance measures of the client or vendor, paying based on profitability or other highlevel performance measures may help somewhat. However, this is likely to be a very weak incentive when compared to the much larger gains or damage created by poaching, unless the performance component is very large (the required condition is the same as given by equation 10), which is not appropriate for situations where the contract is a small part of overall activity of a firm.

Investments in monitoring of poaching activity are a reasonable remedy, although limited by the degree of observability of poaching. Information misuse can often only be observed by the capabilities it provides, making it difficult to establish with certainty a direct link between a market outcome and the misappropriation of information. To resolve this uncertainty it may require extensive access to private information on activities and business processes of the firm 
engaging in poaching, which may be costly and difficult to obtain. Thus, monitoring may be a relatively costly or limited remedy, although extreme circumstances will justify its use.

There is some risk of incentive contracts exacerbating poaching. The primary difficulty is that incentive contracting is often coupled with increased information sharing. For example, for a sales agent to be effective and to direct customers to high profit products to maximize their compensation under a profit-based incentive scheme, the sales agent will need to know a great deal about the relative profitability of different products. This information may have substantial value to the agent (and create substantial losses to the employer) should the agent begin to work for a competitor or should the agent go into the same business as a direct competitor, only distributing the profitable products. This can be modeled generally as an increase in the size of the outside opportunity ( $T_{3}$ increasing) or alternatively the transfer of an additional information asset $I_{2}$, that has is complementary to marketing capability (and thus has no impact on the value created by a coalition of firm 1 and firm 2) but can increase value of the outside opportunity (when marketing is conducted by firms which would not normally have $I_{2}$ ).

As a final note, there is an unusual interaction between poaching and incentive contracting. When a firm can make a non-contractible investment (in the spirit of classic incomplete contracts models, e.g. Hart and Moore, 1990) poaching may actually create a situation of over-investment (rather than the usual problem of under-investment). For example, if a firm is able to use a technology in its primary contract, as well as an outside opportunity that is at least as large as the primary contract, the firm will be able to receive more than $100 \%$ of the surplus generated to the primary contract by their investment. This is interesting, not because it solves the usual underinvestment problem, but because firms that intend to engage in poaching may be appear to be exceeding expectations in their original engagement.

\subsubsection{Transfer of Asset Ownership}


Asset ownership arises as a common mechanism in incomplete contracts analyses because it conveys bargaining power over ex-post surplus and therefore increases incentives for ex-ante noncontractible investment. Transferring asset ownership may be problematic as a mechanism to reduce poaching for several reasons. First, ownership of essential assets or transfer of other assets from the principal to the agent may result in an additional information transfer. For example, transferring a machine that produces a unique product may provide information on the design or the formula for the product itself. In addition, if assets complementary to a piece of poachable information are transferred, the receiving firm now has an increased capability to engage in poaching. Generally, it is optimal to limit asset ownership as much as possible if poaching is a concern, and thus transferring assets has, once again, precisely the wrong effect on the risk of poaching. The analysis is similar to the discussion of incentive contracting - if an addition physical or information asset is transferred that is complementary to outside use, this will increase the scope of poaching.

\subsubsection{Restricted activities}

The idea of excluding specific activities has been considered in the principal-agent literature. A special class of incentive contracting that arises as a consequence of the multi-task principal agent model (Holmstrom and Milgrom, 1991) is an exclusion restriction, which represents a prohibition of effort. For example, firms often prefer employees to work in the office, even if is not strictly necessary, improving incentives to perform work activities by excluding desirable alternative activities that would be available if they were permitted to work from home.

While the idea of exclusion restrictions for incentive purposes seems to have little relationship to poaching, the general idea of restricting activities is quite important. Many types of contractual mechanisms such as non-disclosure agreements, non-competition clauses and limitations of future trade partners can be effective in limiting poaching if the appropriate set of restrictions can be identified at the time of contracting. 
These restrictions have two difficulties. First, the less observable a parties activities are, the more difficult it is to enforce restrictions. It may often be difficult to determine whether a contractor is working for a competitor, or to define in advance the relevant set of competitors and areas of activity that must be excluded. Second, these restrictions create opportunity costs for vendors, which will often require compensation.

\subsubsection{Bonding}

Firms may agree to post a bond to demonstrate willingness or ability to satisfy terms of an agreement. Bonding has two values: first, it guarantees that some resources will be available to compensate the aggrieved party in the case of contractual non-performance, and second, it often introduces a third-party arbitrator to oversee whether the terms of the agreement were met. In general, to the extent that poaching is observable and verifiable by a third party, bonding can be effective. Similarly, there are no potential negative consequences caused by using bonding to solve other contractual problems, provided the bonding process does not require additional information to be shared. ${ }^{13}$

\subsubsection{Reputation}

Reputation is a form of bonding, where the bond itself is implicit. A firm builds up a reputation over time for engaging in appropriate conduct. This foregone opportunism has a cost to the firm, which forms the economic value of their bond (see Kreps, 1990). Should a firm engage in opportunism that were detected, it would be revealed in the marketplace and their reputation would suffer. As with bonding, the primary difficulty of using reputation to reduce poaching is that the poaching needs to be credibly detected in order for reputation to be affected. However, this condition is easier to satisfy for reputation than bonds - the client need only observe and publicize the misdeed, but does not need to be able to prove it to a third-party arbitrator or court.

\footnotetext{
${ }^{13}$ This could become an issue if a party attempted to collect on a bond. The discovery process of a court proceeding or arbitration can often require substantial revelation of information. This may or may not be suitably protected by protective orders that limit the disclosure of information released in trial or arbitration proceedings.
} 


\subsubsection{Relational Contracting}

Relational contracting is the use of loosely defined contractual agreements that set the rules for future negotiations, but allow terms for the agreement to be a process of ongoing negotiation. Relational contracting works best when there are substantial gains from trade and value from repeated interaction (in essence this is the equivalent of a reputational bond that is limited to a single relationship rather than the marketplace as a whole). Relational contracts often lead to greater levels of information sharing than normal arms-length agreements and thus can enhance the opportunities for poaching. However, this sharing may not be risky; the ongoing negotiation process may make more likely that reuse of information is negotiated rather than through poaching. The primary concern of using relational contracting to reduce poaching is that it hinges on observability of poaching - to the extent that poaching is unobservable in the short term, it will not damage the relationship and thus will not be an effective deterrent.

\subsubsection{Auctions and Competitive Bidding}

A very common approach to contracting, especially when key factors (such as the productivity of the vendor or potential set of vendors) are unknown, is to utilize competitive bidding or auction processes. In this mechanism, vendors are prequalified based on an established set of conditions, and then allowed to submit a proposal (or in some cases, simply a bid at a specified cost). In some auctions, the party collecting the bids simply accepts the low cost bidder. In others, the bidding initiates a round of further negotiations with the best bidders to obtain the best pricequality tradeoff.

Competitive bidding structures are likely to be very problematic in situations where poaching is possible. To the extent that engaging in poaching can provide a revenue stream to offset cost, low bidders are disproportionately likely to be the ones that plan to engage in poaching. Moreover, it is already well known that bidders in common value auctions, where the actual (but not necessarily privately estimated) value of the good is the same for all bidders, often succumb to 
"winners curse," where the lowest bidder (the one whose bid was accepted) often wins because they were over optimistic about their cost. A firm that has committed to a contract that cannot be profitable may have less opportunity cost (e.g. reputational damage) associated with engaging in poaching; that is, the reputational damage from poaching or other contractual abuse may still be less than the financial damage of competing the contract on its original terms. In situations where poaching is a real possibility, there is very little possible advantage and potentially substantial disadvantage associated with relying on competitive bidding mechanisms.

\subsection{New Approaches}

There is no standardized list of approaches for solving poaching problems. Several common approaches described above that offer some relief were bonding, monitoring, exclusion of activities (e.g., non-competition agreements), reputation, and relational contracting. There are also several approaches that have been employed in the past that are relevant to solving poaching problems in specific settings. This list is necessarily incomplete, but does give some suggestions of the types of remedies possible. In general these rules divide into obscuring information from the recipient and enhancing observability or detection by the information provider. We provide a few examples below.

Embed information in systems. Information can be partially withheld by embedding it in software or systems. The vendor may have full access to the capabilities of the information but not the information itself.

Encryption/Separation of Models and Data. Confidential and critical data can be encrypted or kept separate from the information that is necessary to reveal to the vendor to perform a service or build a product. One example is that a vendor can be utilized to build an expert system processing engine, while the business rules and models are only available to client personnel.

Modularity of Product. An approach that has been effectively utilized by the Coca-Cola company is to retain complete responsibility for formulating the syrup used to produce their soft drinks, 
while contracting all the manufacturing and bottling capabilities to franchisees and independent suppliers. As long as the product cannot be easily reverse engineered and is never disclosed by the company (qualifying it for trade secret protection) this can be effective.

Modularity of Process. In most cases, poached information only has value if it can be combined with complementary assets. To the extent that information is modular or the complementary physical assets are unique, a firm could distribute different components to different suppliers. This makes it less likely that a disparate base of suppliers could conspire to reconstruct the complete set of information (or information-asset combination) that has economic value.

Seeding. For large bodies of information that are likely to have resale value, "dummy" information could be included that may help reveal the presence of poaching. For example, the insurance company in our example could seed the database with dummy accounts of desirablelooking customers with the addresses of company offices. Thus, if the mailing list were resold, marketing materials sent to the dummy customer would be strong evidence. Map companies historically embedded small mistakes in their maps and atlases, for the same reason.

\section{Conclusion}

In this paper we have presented a theory of poaching, compared poaching to previous theories of contracting risk, examined the conditions under which poaching can occur, considered various remedies for poaching, and illustrated these ideas with case examples and a theoretical model which highlights the importance of complementary assets and product differentiation. Our goal is to contribute additional understanding to the nature of various transaction risks faced by firms that outsource, understand how these risks occur, and present various remedies to solve the problems these risks create. By doing so, we hope to improve academic understanding of the process of contracting for information services and other easy-to-appropriate technologies, and thus to enable practitioners to design better contractual agreements. That is, our objectives 
remain precisely those pursued by mainstream TCE research, but we do so in a domain that has previously received little study.

Overall, our primary conclusion is that poaching is a distinct contractual risk that it is of increasing importance. Moreover, we conclude that it is, at best, not well addressed by classical contracting mechanisms, and at worst exacerbated by remedies for various contractual problems suggested by TCE, Principal-Agent or Incomplete Contracts theory. While we are able to identify a number of mechanisms that might perform better, the optimal contract structure when poaching is a potential difficulty is a promising area of future research from both a theoretical and practical standpoint. 


\section{References}

Alchian, Armen A and Demsetz, Harold (1972). "Production, Information Costs, and Economic Organization," The American Economic Review, (62): 777-795.

Anton, James P. and Dennis Yao (1994). "Expropriation and Inventions: Appropriable Rents in the Absence of Property Rights," The American Economic Review, 84:1: 190-209.

Arrow, K. (1971) Essays in the Theory of Risk Bearing. Markham, Chicago, IL, 1971.

Brynjolfsson, E. and H. Mendelson, (1993). "Information Systems and the Organization of Modern Enterprise," Journal of Organizational Computing. December.

Brynjolfsson, Erik (1994). “An Incomplete Contracts Theory of Information, Technology and Organization,” Management Science, Vol. 40 (12).

Chandler (1977). The Visible Hand. Cambridge, MA: The Belknap Press.

Clemons, E. K. and M. C. Row (1992). "Information Technology and Industrial Cooperation: The Changing Economics of Coordination and Ownership." Journal of Management Information Systems 9(2): 9-28.

Coase, Ronald (1937). “The Nature of the Firm,” Economica 4:386-405.

Grossman Sanford J. and Hart, Oliver D. (1986) "The Costs and Benefits of Ownership: A Theory of Vertical and Lateral Integration," The Journal of Political Economy, 94(4): 691-719.

Hart, Oliver and Moore, John (1990) "Property Rights and the Nature of the Firm," The Journal of Political Economy, 98(6): 1119-1158.

Holmstrom, B. and P. Milgrom (1994). “The Firm as an Incentive System,” American Economic Review 84(4, September): 972-991.

Holmstrom, Bengt and Milgrom, Paul (1991) "Multitask Principal-Agent Analyses: Incentive Contracts, Asset Ownership, and Job Design", Journal of Law Economics \& Organization 7 (special issue):24-52.

Jensen, M. C. and W. H. Meckling (1976). "Theory of the Firm: Managerial Behavior, Agency Costs, and Ownership Structure," Journal of Financial Economics 3: 305-60.

Joskow, Paul L. (1987) "Contract Duration and Relationship-Specific Investments: Empirical Evidence from Coal Markets," American Economic Review, 77 (1): 168-185.

Klein, Benjamin, Crawford, Robert and Alchian, Armen (1978) "Vertical Integration, Appropriable Rents and the Competitive Contracting Process," Journal of Law and Economics. 21: 297-326.

Kleindorfer, Paul and Gunter Knieps (1982). "Vertical Integration and Transaction-Specific Sunk Costs," European Economic Review. Vol. 19 (1): 71-87.

Kreps David M. (1990) A Course in Microeconomic Theory. Princeton, NJ: Princeton University Press.

Lacity, M.C., L.P. Willcocks, and D.F. Feeny (1996). "The Value of Selective IT Sourcing," Sloan Management Review, (Spring): 13-25.

Quinn, James Brian and Frederick G. Hilmer (1994) "Strategic Outsourcing," Sloan Management Review. 35(4): 43-55.

Richmond, William B., Seidmann, Abraham and Whinston, Andrew B. (1992) "Incomplete Contracting Issues in Information Systems Development Outsourcing.” Decision Support Systems 8(5): 459-477.

Shapley, L.S., "A Value for n-Person Games." In Contributions to the Theory of Games, H. Kuhn, \& A. Tucker. Princeton University Press, Princeton, 1953.

Tirole, Jean L. (1988) The Theory of Industrial Organization. Cambridge, MA: MIT Press. 
VanAlstyne, Marshall, Brynjolfsson, Erik and Stuart Madnick. "Why Not One Big Database? Ownership Principles for Database Design,” Decision Support Systems, 1994.

Williamson Oliver E. (1979) “Transaction Cost Economics: The Governance of Contractual Relations,” Journal of Law and Economics, 22 (2): 233-261.

Williamson, Oliver E. (1975) Markets and Hierarchies, Analysis and Antitrust Implications, a Study in the Economics of Internal Organization, New York: Free Press. 


\section{Appendix: Derivation of the Model}

Costs to consumers are strictly increasing in distance from a producer. Therefore, it is possible to derive the length of the line segment served by each producer (and therefore the demand quantity - see Tirole, 1988, p. 280) by locating the point where consumers are indifferent from purchasing between the two producers. This occurs at a point $(\tilde{x})$ when cost to the consumer is equated: $p_{1}+t \tilde{x}^{2}=p_{2}+t(1-\tilde{x})^{2}$. Therefore: $D_{1}\left(p_{1}, p_{2} ; t\right)=\tilde{x}=\frac{p_{2}-p_{1}+t}{2 t}$ and $D_{2}\left(p_{1}, p_{2} ; t\right)=1-\tilde{x}=\frac{p_{1}-p_{2}+t}{2 t}$. Firms simultaneously maximize profits by solving: $\max \pi_{i}=\left(p_{i}-c_{i}\right) D_{i}\left(p_{1}, p_{2} ; t\right)$ which yields the first order condition for each firm (i, facing firm $\left.\mathrm{j}\right)$ : $c_{i}+t+p_{j}-2 p_{i}=0$. The second order conditions are trivially satisfied so this will yield a unique optimum. Solving these two equations simultaneously yields the following optimal price: $p_{i}=\frac{c_{i}+2 c_{j}}{3}+t$ (Equation 2). Plugging this price into the demand function yields Equation 3. To simplify the analysis, we assumed that the entire market was served. This is the case as long as the reservation price exceeds the cost for the most distant customer (the indifferent customer between the two producers). Without loss of generality, we focus on firm 1 . Therefore, the required condition is: $\bar{r}>t q_{1}^{2}+p_{1}=\left(\frac{1}{2}-\frac{c_{1}-c_{2}}{6 t}\right)^{2} t+t+\frac{c_{1}+2 c_{2}}{3}=\frac{5}{4} t+\frac{c_{1}+c_{2}}{2}+t\left(\frac{c_{1}-c_{2}}{6 t}\right)^{2}$. Since the indifference point cannot be greater than $x=1$ by definition, this bounds the last term by $t\left(\frac{1}{2}\right)^{2}$. Therefore, we have: $\bar{r}>\frac{3}{2} t+\frac{c_{1}+c_{2}}{2} \geq \frac{3}{2} t+\max \left(c_{1}, c_{2}\right)$ as appears in the text. 